\title{
Para além do ano 2000, pensar cinema no Brasil
}

\author{
Dr. Antônio Carlos Amancio| antonioamancio@id.uff.br \\ Universidade Federal Fluminense
}

Dr. Fabián Núñez| fabian_nunez@id.uff.br Universidade Federal Fluminense

Palavras-chave:

Estudos cinematográficos; livros sobre cinema; produção bibliográfica

\section{Sumario}

1. Introdução 2. Metodologia 3. Alguns dados

4. Dicionários 5 Alguns temas principais de pesquisa 5.1 Documentário 5.2 Preservação 5.3 Roteiros, adaptações, literatura 5.4 Mercado 5.5 Cinema e Educação 5.6 História do cinema brasileiro 5.7 Cinema brasileiro contemporáneo 5.8 Sobre autores e cineastas 5.9 Coletânea de críticas 5.10 Prospecções abertas 6 Discussão

7 Conclusões 8 Referências

\section{Resumo}

Esta coletânea de dados sobre as publicações sobre cinema no Brasil a partir do ano 2000 não se pretende exaustiva. No entanto, a dificuldade de acesso a toda a bibliografia existente, limitada aos dados disponíveis em alguns sites da Internet não impediu um amplo levantamento das obras editadas. Aos livros editados foram acrescentadas teses e dissertações defendidas nas principais universidades do país. Não foram considerados como pertinentes os estudos sobre televisão, um campo à parte. Trata-se de uma pioneira contribuição aos estudos da área, a ser atualizado permanentemente.

\section{Cómo citar este texto:}

Antônio Carlos Amancio y Fabián Núñez (2017): "Para além do ano 2000, pensar cinema no Brasil", en Miguel Hernández Communication Journal, nº 8 , pp. 121 a 149. Universidad Miguel Hernández, UMH (Elche-Alicante). Recuperado el _ de de 20 de: [link del artículo en mhjournal.org] 


\title{
Beyond the year 2000, think cinema in Brazil
}

\author{
Dr. Antônio Carlos Amancio| antonioamancio@id.uff.br \\ Universidade Federal Fluminense
}

Dr. Fabián Núñez| fabian_nunez@id.uff.br

Universidade Federal Fluminense

\author{
Keywords \\ Film studies; books on cinema; bibliographic \\ production \\ Summary \\ 1. Introduction. 2. Methodology. \\ 3. Some data 4. Dictionaries 5 Some Key \\ Research Topics 5.1 Documentary 5.2 \\ Preservation 5.3 Sketches, adaptations, literature \\ 5.4 Market 5.5 Cinema and Education \\ 5.6 History of Brazilian cinema 5.7 Contemporary \\ Brazilian Cinema 5.8 About authors and \\ filmmakers 5.9 Collection of critiques \\ 5.10 Open Prospections 6 References \\ 7 Conclusions 8 References
}

\begin{abstract}
This data collection of publications on cinema in Brazil since the year 2000 is not intended to be exhaustive. However, the difficult access to all the existing literature, limited to the data available on some websites, did not prevent a broad data survey of published works. Theses and dissertations defended in the leading universities of the country were added to the edited books. Studies on television, which is considered an apart field, were not taken into consideration. This is a pioneering contribution to the field studies, to be permanently updated.
\end{abstract}

\section{How to cite this text:}

Antônio Carlos Amancio y Fabián Núñez (2017): "Beyond the year 2000, think cinema in Brazil”, en Miguel Hernández Communication Journal, n8, pp. 121 to 149 Universidad Miguel Hernández, UMH (Elche-Alicante). Accessed 20 in: [paper link in mhjournal.org] 


\section{Introdução}

Para o cinema brasileiro, os anos 2000 começam em um cenário que se pode chamar de pós-Retomada, depois de superado o impasse da extinção dos órgãos estatais voltados para a atividade na década de 1990. Se a Retomada foi o recomeço tardio da produção de filmes, a pós-Retomada é configurada através de dois eventos que marcam o re-engajamento político das categorias profissionais ligadas ao audiovisual. São eles a realização do $3^{\circ}$ Congresso Brasileiro de Cinema (CBC) em 2000, e a criação da Agência Nacional do Cinema (Ancine), em 2003, esta última no mesmo modelo de outras instituições marcadas pelo ideário neoliberal (BARONE, 2011, p. 916-932).

Um dos itens da agenda política proposta pelo $3^{\circ} \mathrm{CBC}$ foi a sugestão de se criar um fórum permanente de escolas de cinema e centros de formação profissional para dialogar com o Estado e com o Mercado (FORCINE, 2015), que foi efetivamente criado em 2001 com o nome de Fórum Brasileiro de Ensino de Cinema e Audiovisual (FORCINE). ${ }^{1}$ Se as quatro mais tradicionais escolas de cinema do país - as Universidade de São Paulo (USP), Universidade de Brasília (UnB), Universidade Federal Fluminense (UFF) e Fundação Armando Álvares Penteado (FAAP) - criadas desde a segunda metade do século XX já tinham se consolidado como instituições de ensino, pesquisa e extensão, voltadas para a prática e a reflexão da área, os anos 2000 vão ver a aparição de muitas escolas de nível superior de formação para o audiovisual.

Assim, já em 2003 teremos 22 escolas registradas no Ministério da Educação (MEC), em nível de Graduação, com seu foco principal na produção de filmes. Tal evolução acompanha de perto o crescimento do mercado e a maior disponibilidade dos novos equipamentos digitais de registro e edição. Em 2011, já são 53, conforme informação do próprio FORCINE, segundo o relatório do projeto Mercado audiovisual e formação profissional: o perfil dos cursos superiores em cinema e audiovisual no Brasil. ${ }^{2}$ Se agregarmos a este total, buscado no site oficial de escolas ativas e cadastradas no MEC a partir dos termos Audiovisual, Cinema, Imagem e Som, Midialogia e Animação, definidos como

\footnotetext{
${ }^{1}$ O FORCINE é uma sociedade civil sem fins lucrativos que congrega escolas de cinema.Atualmente conta vinte e duas (22) Instituições de Ensino associadas. Ver:: $<$ http://forcine.org.br/site/>. Acesso em 04/11/2016.

2 Projeto desenvolvido por Danielle Christine Leite Ribeiro e Alessandra Meleiro, ambas da Universidade Federal de São Carlos (UFSCar), Guilherme Carvalho da Rosa da Universidade Federal de Pelotas (UFPel) e Luciana Rodrigues Silva da FAAP, no âmbito do Projeto Iniciação Científica do CNPq (Conselho Nacional de Desenvolvimento Científico e Tecnológico).
} 
metodologia de busca, outros cursos filiados ao Fórum (ligados às áreas de Comunicação, Artes ou Arquitetura, sem a menção explícita ao cinema ou ao audiovisual no nome), este total aumenta para 87 cursos de Graduação em Instituições de Ensino Superior. Dessas, 30\% são públicas e as restantes, privadas.

Existe um único Curso de Licenciatura ${ }^{3}$, que se encontra na UFF, enquanto que nas instituições privadas é maior a oferta de cursos tecnológicos, uma formação profissionalizante visando áreas específicas. Os restantes são Bacharelados, de formação generalista, com base científica ou humanística, voltados para a o exercício de atividade profissional, acadêmica ou cultural. A incidência maior desses cursos se dá na região Sudeste (59\%), seguidos pela região Nordeste (18\%), Sul (13\%), Centro-Oeste (7\%) e Norte (3\%). Esta distribuição é importante porque demonstra a territorialização do país em função das necessidades do mercado de trabalho e do potencial de expressão e difusão audiovisual. Neste sentido, por estarem mais perto dos centros de produção e exibição, os estados do Sudeste (Espírito Santo, Minas Gerais, Rio de Janeiro e São Paulo) levam visível vantagem sobre, por exemplo, os estados do Norte (Acre, Amapá, Amazonas, Pará, Rondônia, Roraima e Tocantins).

Esta geopolítica define a intensidade da atividade cinematográfica no país e consequentemente as reservas culturais audiovisuais de que se servirão os estudantes, produzindo textos, teses e artigos de reflexão sobre o cinema e o audiovisual em variadas tonalidades, historiográficas, teóricas e ensaísticas. Até porque nos cursos a maioria dos currículos privilegia o eixo "Realização e Produção", seguido de "Teoria, Análise, História e Crítica".

Portanto, o novo século é marcado pela ampla expansão do ensino universitário no Brasil, o que também inclui a pós-graduação. As pesquisas sobre cinema tradicionalmente estão inseridas nos Programas de PósGraduação em Comunicação, embora também possamos encontrar investigações sobre cinema em áreas como História, Artes, Letras, Ciências Sociais, Educação, Ciência da Informação, Economia, Design e Arquitetura. Se até os anos 1980, existiam no Brasil seis (6) Programas de Pós-Graduação em Comunicação, em 2013, esse número pula para sessenta e três (63). ${ }^{4}$ No

${ }^{3}$ Os Cursos de Licenciatura no Brasil, que outorgam o título acadêmico de Licenciado aos seus egressos, são equivalentes aos chamados Cursos de Professorado em países hispânicos, ou seja, são cursos voltados para a formação de professores.

4 Documento de Área 2013 - Ciências Sociais Aplicadas I. Disponível em: $<$ https://www.capes.gov.br/images/stories/download/avaliacaotrienal/Docs_de 
entanto, é importante ressaltar que entre esse grande número são apenas alguns poucos Programas que contam, de fato, com áreas de pesquisa voltadas especificamente para os estudos de cinema e audiovisual. Também frisamos que entre todos esses Programas, até setembro de 2016, somente três são especificamente dedicados aos estudos de cinema, sendo que apenas um em nível de Mestrado e Doutorado, ${ }^{5}$ ao qual se soma o recém-aprovado (janeiro de 2017) Programa de Pós-Graduação em Cinema e Audiovisual (PPGCine) da UFF, também com esta dupla qualificação.

Portanto, estes dados nos dão uma medida da expansão do campo de reflexão sistemática sobre cinema e audiovisual no Brasil. Há que se considerar os diferentes níveis de produção escrita, de monografias a dissertações e teses, que nem sempre serão publicadas, juntamente com a produção especialmente bibliográfica, fruto de pesquisas específicas. E também a existência de editoras universitárias capazes de fazer circular sua produção interna, sem a possibilidade de recorrer às grandes editoras ou aos veículos de maior circulação no país. Assim que uma realidade do presente século é o aumento exponencial de pesquisas sobre cinema nas universidades brasileiras. No entanto, do ponto de vista quantitativo, é uma pequena parcela dessas teses e dissertações que alimenta o setor editorial, em publicações editadas, sobretudo, com o auxílio de fundações estaduais de amparo à pesquisa científica.

\section{Metodologia}

Para realizarmos este trabalho foram consultadas as seguintes fontes para a composição da bibliografia, com a colaboração dos estudantes Lucas Fratini e Vinicius Spanghero do Curso de Bacharelado em Cinema da UFF: sites da Cinemateca Brasileira, do Mnemocine, das várias editoras brasileiras a partir das palavras-chave "cinema" e "cinema brasileiro", de algumas bibliografias de textos publicados e de informações avulsas colhidas entre pesquisadores. Outro critério em nossa pesquisa são as publicações exclusivamente voltadas ao cinema brasileiro.

_area/Ciencias_Sociais_Aplicadas_doc_area_e_comiss\%C3\%A3o_16out.pdf $>$. Acesso em: 09/02/2017.

5 Trata-se dos Programas de Pós-Graduação em Meios e Processos Audiovisuais da Universidade de São Paulo (USP) - com Mestrado e Doutorado -, a PósGraduação em Imagem e Som da Universidade Federal de São Carlos (UFSCar) e o Mestrado Interdisciplinar em Cinema da Universidade Federal de Sergipe (UFS). 
Por razões de espaço, não pudemos citar publicações de caráter mais inter e multidisciplinar, como Cinema e História, Cinema e Psicanálise, Cinema e Filosofia, entre muitos outros, bastante comum em nossas livrarias a partir do ano 2000. Exceção será feita em relação a Cinema e Educação, uma vez que tal bibliografia dialoga diretamente com o Curso de Licenciatura da UFF, instituição onde os autores do presente artigo lecionam. Portanto, a natureza da investigação e a extensão do campo consultado possibilitam apenas um pálido dimensionamento do universo escolhido. Tampouco nos foi possível recuperar todas as antologias de textos - se os limitamos, foi por uma questão metodológica e de facilidade de acesso. Quanto às Associações e sua produção, recorremos aos sites da SOCINE (Sociedade Brasileira de Estudos de Cinema e Audiovisual) e do FORCINE, sempre contando com a providencial ajuda de amigos pesquisadores para dirimir algumas dúvidas.

Se consideramos apenas a produção bibliográfica que nos foi possível prospectar sobre o campo cinema/audiovisual, sem nos atermos às coletâneas (anais da SOCINE e outros), às reedições (que contaram com autores e livros clássicos) ou catálogos de mostras e festivais (às vezes primorosos estudos sobre matéria cinematográfica editada por Centros Culturais) ou ainda revistas acadêmicas ou não, teremos uma noção do universo de interesse editorial contemporâneo, aqui apresentados de modo fragmentário, sintético e não intensivo. A seguir apresentaremos alguns dos itens ligados à extensa bibliografia lançada no período.

\section{Alguns dados}

Os pesquisadores de cinema e audiovisual do Brasil estão agrupados em uma associação chamada Sociedade Brasileira de Estudos de Cinema e Audiovisual - SOCINE, criada em novembro de 1996 para promover o intercâmbio de pesquisas e estudos de cinema em suas mais diferentes manifestações. Ela é voltada essencialmente para pesquisadores da área acadêmica e hoje conta com mais de 1600 associados. É a SOCINE o principal elo de ligação entre escolas, programas, autores e leitores do que se escreve sobre cinema e audiovisual no Brasil, sendo responsável pela edição de livros (os anais dos encontros ou edições especiais) e a Revista Rebeca - Revista Brasileira de Estudos de Cinema e Audiovisual ${ }^{6}$, atualmente em sua nona edição.

A SOCINE, em seus encontros anuais, desenvolve uma metodologia de apoio aos grupos de pesquisa emergentes, reservando em sua agenda um horário especial para apresentação de seus trabalhos. São os Seminários Temáticos

${ }^{6}$ Ver: <http:/ /www.socine.org.br/rebeca>. Acesso em 12/10/2016. 
(ST), com duração de dois anos, renováveis por mais dois, que ao lado das mesas e dos painéis (para mestrandos) dão conta da enorme diversidade de temas em discussão. Além dos anais do congresso, a SOCINE também publica livros, físicos e virtuais (e-books), cuja curadoria fica a cargo dos organizadores do evento daquele ano. Assim como são editados livros oriundos de pesquisas apresentadas em Seminários Temáticos do congresso, que recebem auxílio financeiro para sua publicação.

\section{Dicionários}

Entre as compilações de filmes, autores, diretores ou movimentos selecionamos alguns dos mais importantes aparecidos no período. Comecemos pela Enciclopédia do Cinema Brasileiro, organizada por Fernão Ramos e Luiz Felipe Miranda, editada pelo SENAC de São Paulo em 2000, obra de referência contando com mais de 700 verbetes temáticos e de personalidades, artistas e técnicos, fartamente ilustrado, já em sua terceira edição revista e ampliada (2012). O Dicionário de filmes brasileiros: longa-metragem, de Antônio Leão da Silva Neto, publicado pela Editora do Autor em 2002 (e atualizado em 2009) foi consagrado como o mais completo levantamento sobre a filmografia brasileira, com sinopses, comentários, informações e fichas técnicas completas dos longas nacionais produzidos desde 1908. Igualmente seletivo é o livro Grandes personagens da história do cinema brasileiro (1960-1969), de Eduardo Giffoni Flórido, pela Fraiha em 2006, tratando de 71 personagens, com biografia e fotos. O pesquisador Jurandyr Noronha publica em 2008 duas obras de importância, ambas pela EMC do Rio de Janeiro: Dicionário de cinema brasileiro: de 1896 a 1936, do nascimento ao sonoro e o Dicionário de cinema brasileiro: os que vieram de outras terras.

Por sua vez, Astros e estrelas do cinema brasileiro, de Antônio Leão, foi lançado em 2010 pela Imprensa Oficial do Estado de São Paulo (IMESP), no mesmo ano em que o autor e editora lançam o Dicionário de fotógrafos do cinema brasileiro. É também Antônio Leão quem publica em 2011, pelo IBAC paulista, o Dicionário de filmes brasileiros: curta e média-metragem, catalogando os exemplares desses formatos. Também pela Coleção Aplauso, da IMESP, é o Cinema da Boca: dicionário de diretores, de 2005, organizado por Alfredo Sternheim, sobre os realizadores da Boca do Lixo, reduto paulistano de produção de cinema popular. Em 2013 sai o Dicionário de cinema brasileiro: filmes de longa-metragem produzidos entre 1909 e 2012 de Mauro Baladi, pela paulista Martins Fontes. 
Cabe ressaltar a importância da coleção Aplauso da Imprensa Oficial do Estado de São Paulo, que lançou livros em papel e os disponibilizou on-line. ${ }^{7}$ Sob a curadoria do crítico de cinema Rubens Edwald Filho, a coleção foi iniciada em 2004, sendo dividida nas séries Perfil, Teatro Brasil, Cinema Brasil, Dança e TV. Em relação a cinema e a TV, as séries se dividem em publicação de roteiros de filmes brasileiros, coletâneas de artigos de críticos de cinema, dicionários sobre personalidades do cinema brasileiro e estudos monográficos sobre diretores, atores e atrizes. Até outubro de 2016, o catálogo dedicado ao cinema é composto por mais de 50 títulos. Frisamos que um dos sucessos da Coleção Aplauso é o preço acessível dos livros físicos, além da política de download gratuito de todas as obras da coleção pelo site da IMESP.

\section{Alguns temas principais de pesquisa}

\subsection{Documentário}

Um dos temas que ganharam bastante visibilidade desde meados dos anos 1990 é o documentário. Podemos afirmar que se trata de um fenômeno mundial que encontramos no aumento da produção de filmes de um gênero tradicionalmente pouco absorvido pelo mercado. E não são apenas nas telas aonde o documentário conquistou mais visibilidade - também no meio acadêmico, cultural e no mercado editorial. Logo, o número de livros, pesquisas universitárias e mostras de filmes dedicados exclusivamente ao cinema não ficcional e/ou a determinados documentaristas sinaliza esse aspecto. Outro sintoma desse fenômeno é a presença nas grades curriculares dos cursos de Cinema de disciplinas (optativas e, em vários casos, obrigatórias) dedicadas exclusivamente ao documentário. O mesmo podemos encontrar na pós-graduação, uma vez que vários pesquisadores se dedicam a estudar o gênero - e, não por acaso, são as suas pesquisas que alimentam o mercado editorial sobre documentário.

Além disso, não podemos deixar de mencionar a importância conquistada pelo Festival Internacional de Documentários É tudo verdade/It's all true, realizada anualmente desde 1996. É o principal festival no Brasil dedicado inteiramente ao gênero e, por conseguinte, a janela mais relevante a esse tipo de filme no país. Sob a curadoria do crítico Amir Labaki, o festival ainda possui atualmente um programa televisivo apresentado por seu curador no Canal Brasil (o principal canal por assinatura dedicado exclusivamente ao cinema brasileiro), além de ter editadoo livro intitulado O cinema do real (São Paulo,

${ }^{7}$ Consultar em: http://aplauso.imprensaoficial.com.br/. Acesso em: 04/11/2016. 
Cosac Naify, 1ª edição em 2005 e $2^{a}$ edição em versão portátil em 2014). Organizada por Labaki e Maria Dora Mourão, a obra reúne textos que abordam as principais discussões levantadas no festival, além de uma parte dedicada à produção documental latino-americana. Labaki publica mais três livros de sua autoria: É tudo verdade: reflexões sobre a cultura do documentário (São Paulo, Francis, 2005), uma coletânea de artigos do crítico,Introdução ao documentário brasileiro (São Paulo, Francis, 2006), a rigor, uma brevíssima história do cinema documentário brasileiro, e É tudo cinema - 15 anos de É tudo verdade (São Paulo, IMESP, 2010), dedicada à memória do festival, com histórias de bastidores e fotos. Também organiza o livro $A$ verdade de cada um (São Paulo, Cosac Naify, 2015), que reúne textos de documentaristas estrangeiros e brasileiros.

Diante dessa recente valorização do documentário é reeditado o livro Cineastas e imagens do povo (São Paulo, Companhia das Letras, 2003) de Jean-Claude Bernardet. Trata-se de uma obra considerada "clássica", fruto de uma pesquisa pioneira sobre o documentário brasileiro dos anos 1960 e 1970. A nova edição recebe um acréscimo de dois textos, um sobre o documentário histórico dos anos 1980 (Silvio Tendler e Ana Carolina) e o outro, sobre o uso da entrevista no documentário brasileiro contemporâneo. Outras obras que se tornaram referenciais são $O$ espelho partido: tradição e transformação do documentário (Rio de Janeiro, Azougue, 2004) de Silvio Da-Rin e Documentário no Brasil: tradição e transformação (São Paulo, Summus, 2004), organizado por Francisco Elinaldo Teixeira, que busca traçar um panorama histórico do documentário no cinema brasileiro.

Outras obras dedicadas à reflexão sobre o cinema não ficcional são Mas afinal... o que é mesmo documentário? (São Paulo, Senac, 2008), de Fernão Pessoa Ramos, que aborda os principais aspectos teóricos sobre o documentário e Filmar o real: sobre o documentário brasileiro contemporâneo (Rio de Janeiro, Zahar, 2008) de Consuelo Lins e Claudia Mesquita, que tece reflexões sobre o então "estado das coisas" no Brasil sobre documentário. Outra obra que constata o crescimento do gênero em nossas telas é Documentário nordestino: mapeamento, bistória e análise (São Paulo, Annablume, 2008), de Karla Holanda, que analisa a produção documental nos estados brasileiros da Região Nordeste, de 1994 a 2003. Sobre a mesma região, mas sob um viés histórico, mencionamos Dos homens e das pedras: o ciclo do cinema documentário paraibano (1959-1979) (Niterói,EdUFF, 1998), de José Marinho.

Considerado um dos principais documentaristas brasileiros, Eduardo Coutinho é objeto de estudo de várias pesquisas. Destacamos $O$ documentário de Eduardo Coutinho: televisão, cinema e vídeo (Rio de Janeiro, Zahar, 2007), de 
Consuelo Lins, Edificio Master: um estudo sobre face em entrevistas de cinema documentário (São Paulo, EDUC, 2013), de Maria Estela Maiello Modena, e A personagem no documentário de Eduardo Coutinho (Campinas, Papirus, 2014) de Claudio Bezerra. De origem não acadêmica é Eduardo Coutinho: o homem que caiu na real (Santa Maria da Feira, Cineclube da Feira, 2003) do crítico Carlos Alberto Mattos. Por sua vez, uma obra que podemos dizer que já nasceu incontornável sobre o cineasta em questão é Eduardo Coutinho (São Paulo, Cosac Naify, 2013), organizado por Milton Ohata, publicado em homenagem aos 80 anos do realizador. Em suas 704 páginas, o livro reúne textos originais do próprio cineasta, além de ensaios e depoimentos de colaboradores em seus filmes.

\subsection{Preservação}

Uma das áreas de estudo que praticamente ainda não foi absorvida pelo mercado editorial é o campo da preservação audiovisual. Um tema que ganhou destaque nas pesquisas sobre cinema brasileiro nas universidades, o que demonstra um maior interesse pelo assunto no país, produzindo, por conseguinte, uma reflexão em Língua Portuguesa em uma área cuja expressa maioria do conhecimento se encontra em idiomas estrangeiros. O debate em torno da preservação audiovisual inaugura o novo século, não somente por conta da transição tecnológica do fotoquímico para o digital, mas também devido à crise da Cinemateca do Museu de Arte Moderna do Rio de Janeiro, em 2002, que mobiliza o setor e a classe cinematográfica brasileira.

Por sua vez, em termos de políticas públicas, encontramos uma ambiguidade no Ministério da Cultura (MinC) durante os dois mandatos presidenciais de Lula. Testemunhamos a existência de políticas públicas de descentralização da produção audiovisual e de ações afirmativas enquanto que no âmbito da preservação audiovisual constatamos um forte investimento e centralidade em uma única instituição pública, a Cinemateca Brasileira, que reivindica para si a totalidade de uma política de preservação audiovisual de caráter nacional. É inconteste o salto qualitativo da Cinemateca Brasileira no começo do século XXI, assim como o descrédito em uma ação em rede e a falta de continuidade de uma equipe técnica. A criação da ABPA (Associação Brasileira de Preservação Audiovisual), em 2008, que reúne profissionais de arquivos públicos e privados, é fruto dessa mobilização. ${ }^{8}$ Portanto, é sintomático que na virada dos anos 2000/2010, várias pesquisas sobre preservação audiovisual tenham ocorrido, pois o tema se encontrava candente e o meio em busca de

${ }^{8}$ Ver < http:/ /www.abpreservacaoaudiovisual.org>. Acesso em out. 2016. 
mobilização. Trata-se de um campo praticamente virgem para textos em Português.

A rigor, um dos primeiros livros sobre o tema é A Cinemateca Brasileira: das luzes aos anos de chumbo (São Paulo, EdUnesp, 2010), de Fausto Douglas Correa Júnior, inicialmente uma dissertação de mestrado. Em 2009, mais duas investigações dedicadas à história do arquivo paulista são defendidas por dois de seus funcionários de carreira, a saber, A Cinemateca Brasileira e a preservação de filmes no Brasil, tese de doutoramento de Carlos Roberto de Souza, e A experiência brasileira na conservação de filmes: um estudo de caso, dissertação de Fernando Coelho, ambas defendidas na USP. Por sua vez, a Cinemateca do MAM é objeto de estudo da dissertação A preservação cinematográfica no Brasil e a construção de uma cinemateca na Belacap: a Cinemateca do Museu de Arte Moderna do Rio de Janeiro (1948-1965), de José Quental, então funcionário da instituição, defendida na UFF em 2010.

Também podemos encontrar pesquisas sobre outras instituições de guarda ou estudos de caso sobre determinados acervos: a dissertação Rastros de perícia, método e intuição: descrição do arquivo Paulo Emílio Salles Gomes, de Olga Futemma, funcionária de carreira da Cinemateca Brasileira, defendida na USP em 2006; Preservação e restauração cinematográficas no Brasil: a restauração do acervo de HikomaUdhiara, de Caio Júlio Cesaro, tese de doutorado defendida em 2007 na Universidade Estadual de Campinas (Unicamp); Entre memória e preservação: uma etnografia sobre a implantação da Cinemateca Capitólio em Porto Alegre, de Simone Rolim Moura, dissertação defendida na Universidade Federal do Rio Grande do Sul (UFRGS) em 2008 e a dissertação Filmes domésticos: uma abordagem a partir do acervo da Cinemateca Brasileira, de Lila Silva Foster, defendida em 2010 na UFSCar.

Outro tema de pesquisa são os casos de restauração de filmes brasileiros, como as dissertações Entre grãos e pixels, os dilemas éticos na restauração de filmes: o caso Terra em transe, de Marco Dreer Buarque, defendida em 2011 na Fundação Getúlio Vargas do Rio de Janeiro (FGV-RJ), Mulher:a trajetória do som do primeiro longa-metragem synchronizado da Cinédia, de Joice Scavone Costa e Materialidade e espectatorialidade do DVD: a Coleção Joaquim Pedro de Andrade, de Roberto Souza Leão, ambas defendidas na UFF. Por fim, não podemos deixar de frisar o primeiro estudo sistemático sobre políticas públicas na área no país, a tese de doutoramento intitulada Politicas para a preservação audiovisual no Brasil (19952010) ou: "para que eles continuem vivos através de outros modos de vê-los" de Laura Bezerra, defendida na Universidade Federal da Bahia (UFBA), em 2014. 


\subsection{Roteiros, adaptações, literatura}

A interface entre literatura e o cinema continua disputando o interesse de estudantes e profissionais do ramo dos espetáculos audiovisuais, por ser um domínio em que se mesclam as mais diversas teorias, reivindicando a independência das técnicas e os modos de expressão de uma com relação ao outro. Apesar de constituírem sistemas semióticos distintos, essas modalidades narrativas se cruzam e se tangenciam, proporcionando leituras variadas. Entre as mais importantes do período, registramos Literatura, cinema e televisão (São Paulo: Senac, 2003), coletânea organizada por Tania Pellegrini e outros. No mesmo sentido foi publicada a coletânea Narrativas ficcionais: da literatura às midias audiovisuais, organizada por Suely Fadul Villibor Flory e lançada em 2003 pela Arte \& Ciência de São Paulo.

Em 2007 foi editado o livro O chão da palavra: cinema e literatura no Brasil de José Carlos Avellar, no Rio de Janeiro, pela Rocco e no ano seguinte a EdUFMG colocou no mercado o igualmente importante $A$ literatura através do cinema: realismo, magia e a arte da adaptação, de Robert Stam. Mesmo ano em que José Roberto Sadek lançou Telenovela: um olhar do cinema, pela Summus de São Paulo, livro em que compara a estrutura dramática do cinema clássico com a das telenovelas, centrado no estudo das narrativas. O ano 2008 também foi quando Roteiro para as novas mídias, de Vicente Gosciola, é editado pelo Senac.

A especificidade do imaginário nordestino é dissecada por Sylvie Debbs em Cinema e Literatura no Brasil: os mitos do sertão, emergência de uma identidade nacional, posto em circulação pela Editora ComArte de Belo Horizonte, em 2010. Da mesma autora éCinema e Cordel: "jogo de espelho", editado em Fortaleza pela Interarte Editora/Lume Filmes em 2014, que atualiza e amplia a questão já estudada em Cordel, Lampião e Cinema na Terra do Sol de Adriana Cordeiro Azevedo, editada pela Ferreira Studio do Rio de Janeiro em 2004. Outra importante contribuição veio em 2014 com o livro Literatura e Cinema: encontros contemporâneos, organizado por Ana Maria Lisboa de Mello, lançado pela Dublinensede Porto Alegre. Por sua vez, Julio Alfradique e Carla Lima fizeram um levantamento imprescindível em seu Da literatura para o cinema: guia de 1780 escritores e suas obras adaptadas, publicado pela Mirabolante em 2010.Uma obra curiosa, que analisa em profundidade o problema da transcriação, é o livro Adaptação intercultural: o caso de Shakespeare no cinema brasileiro de Marcel Vieira Barreto Silva, publicado pela EdUFBA em 2013.

Ao lado das adaptações e nem sempre podendo negar sua filiação literária, o campo dos estudos de roteiro teve um enorme desenvolvimento. Foram 
lançamentos e re-edições que tornaram o assunto dos mais visíveis e atuais, principalmente nos últimos anos, depois da sanção da Lei Federal no 12.485, de 12 de setembro de 2011, que obrigou os canais de TV por assinatura a veicularem um certo volume de conteúdo brasileiro em suas grades de programação. Isto acelerou o processo de produção de programas e séries, abriu a possibilidade da inscrição de novos roteiristas no mercado e consequentemente da ampliação do campo editorial sobre o assunto. Em 2001 contamos com Me alugo para sonbar, de Gabriel García Márquez, pela Casa Jorge, do Rio de Janeiro, em 2002 com Escrevendo curtas, de Luiz Gustavo Bayão (Rio de Janeiro, LGB Comunicações) e o manual prático Como formatar seu roteiro de Hugo Moss, pela Aeroplano, também do Rio.

Em 2003 aparece uma obra mais substancial, O poder do climax, de Luís Carlos Maciel, pela Record. No ano seguinte é a vez de Vende-se em 30 segundos: Manual do Roteiro para Filme Publicitário, escrito por Tiago Barreto e editado pelo Senac. Então vem a reedição de $A$ jornada do escritor: estruturas míticas para escritores, de Christopher Vogler, da Nova Fronteira do Rio de Janeiro em 2006. Linda Seger aparece com o seu Como criar personagens inesqueciveis, pela paulista Bossa Nova também em 2006. Mesmo ano em que Felipe Moreno, a partir de fundamentos da psicanálise lança Dupla personalidade para um roteiro, pela Célebre Editora de São Paulo.

Story: substância, estrutura, estilo e os princípios da escrita de roteiro, o já clássico manual de Robert McKee foi relançado pela Arte \& Letra de Curitiba, em 2007, enquanto Flavio Campos, no mesmo ano edita o seu Roteiro de Cinema e Televisão, pela Zahar. Linda Seger lançou, no mesmo ano de 2007, dois de seus livros: $A$ arte da adaptação: como transformar fatos e fiçãa em filme e Como aprimorar um bom roteiro, ambos pela Bossa Nova. Comprovando a eficiência de seu esforço pioneiro, Doc Comparato lançou mais uma edição do seu já clássico Da criação ao roteiro, o primeiro livro brasileiro de sucesso sobre o assunto, agora pela Summus, em 2009. E a prolífica Linda Seger, acompanhada por Edward J. Whetmore, lança Do roteiro para a tela, também pela Bossa Nova, ainda em 2009. Diretamente do meio acadêmico Roberto L. Duarte, da UFBA viu editado o seu Primeiro Traço: manual descomplicado de roteiro, em 2009, e Sérgio Puccini Júnior, também da academia, lançou pela Papirus de Campinas, no mesmo ano, o Roteiro de Documentário. Syd Field é editado pela Arte \& Letra de Curitiba com o seu Roteiro: os fundamentos do roteirismo, em 2009, mesmo ano de Manual de Roteiro, ou manuel, o primo pobre dos manuais de cinema \& tevê, de Newton Cannito e Leandro Saraiva, em sua reedição do sucesso lançado em 2004 pela Conrad de São Paulo. Em 2015, é lançadoRoteiro de roteiro, de Roman Bruni, pela Conexão.Net, em sua $4^{a}$ edição. 


\subsection{Mercado}

Este campo de estudos só muito recentemente passou a ser objeto de uma investigação acadêmica mais sistemática e já podemos identificar a evolução de uma reflexão sobre as políticas estatais, as contradições do mercado brasileiro, os esforços de independência, os erros e acertos das experiências de intervenção em um terreno historicamente ocupado pelo produto estrangeiro. Neste trabalho excluímos quase que integralmente a vertente televisiva, por ser pensada quase que como um domínio à parte, por mais que as relações cinema e televisão tenham se estreitado desde o início do atual século.

Alguns dos principais estudos sobre o mercado, que envolvem políticas públicas, distribuição e exibição são Cinema, desenvolvimento e mercado, de Paulo Sergio Almeida e Pedro Butcher, publicado pela Aeroplano em 2003, Cinema Digital: um novo cinema? e A hora do cinema digital, de Luiz Gonzaga Assis de Luca, ambos editados pela IMESP, respectivamente em 2004 e 2009; em 2007, pela Marco Zero de São Paulo, o documentarista Mario Kuperman lança Fracasso de bilheteria: trếs ensaios sobre a difusão da cultura no Brasil, abrangendo educação, exibição e difusão. De André Piero Gatti tivemos A distribuição comercial cinematográfica e $A$ exibição cinematográfica ontem, hoje e amanhã, editados pela Secretaria Municipal de Cultura de São Paulo, ambos em 2008, e do mesmo autor, em 2010, Cinema e mercado, editado também em São Paulo pela Escrituras-Iniciativa Cultural. Um estudo pioneiro sobre as políticas públicas no setor audiovisual no âmbito do Mercosul é Viz̧inhos distantes: circulação cinematográfica no Mercosul, de Denise Mota da Silva, publicado em 2007, pela Annablume. Entre as re-edições notáveis, temos em 2008 o seminal Estado e cinema no Brasil de Anita Simis, editado também pela Annablume.

A partir de 2009, se viu nas livrarias uma coleção voltada exclusivamente para a indústria cinematográfica e audiovisual brasileira. Editada em São Paulo pela Escrituras, é composta pelos livros Cinema e Políticas de Estado: da Embrafilme à Ancine, escrito por Melina Marson (Volume I, 2009), Cinema: Economia política, (Volume II, 2010), organizada por Alessandra Meleiro, assim como o terceiro volume, Cinema e Mercado. Em 2010, Hadija Chalupe da Silva lança O filme nas telas: a distribuição do cinema nacional, pela Ecofalante, ao mesmo tempo em que Leandro Valiati apresenta Economia da cultura e cinema: notas empiricas sobre o Rio Grande do Sul pela mesma editora. Os cenários tecnológicos e institucionais do cinema brasileiro na década de 90, de João Guilherme Barone Reis e Silva foi um livro publicado em 2009 pela Sulina de Porto Alegre, revendo aquele período de grandes rupturas e transformações na atividade cinematográfica .Film busine \$\$, o negócio do cinema, organizado por Adriana Dias e Letícia de Souza Barbosa em 
2010, traz artigos do diretor da Sony Pictures, do atual diretor da Cinépolis no Brasil e de vários produtores, editado pela Elsevier, do Rio de Janeiro

Já em 2012 surgiram Políticas públicas e regulação do audiovisual, organizado por Rafael dos Santos e Angelica Coutinho pela CRV de Curitiba, Cinema Brasileiro no século 21, de Franthiesco Ballerini, lançado em São Paulo pela Summus e Discursos, políticas e ações: processos de industrialização do campo cinematográfico brasileiro, escrito por Lia Bahia e editado pelo Itaú Cultural/Iluminuras em São Paulo. Em 2013, Arthur Autran lança o seu O pensamento industrial cinematográfico brasileiro em São Paulo, pela Huicitec, precedido por Marcelo Ikeda, que ainda em 2013 demonstra como captar recursos para o audiovisual com o seu Leis de Incentivo, lançado pela WSET, que se ampara no seu Lei da ANCINE comentada, de 2012, da mesma WSET para analisar as políticas públicas para o cinema.

Quanto à exibição, os trabalhos geralmente se detêm na recuperação de salas de cinema de prestígio no passado, seja por sua localização, arquitetura ou mesmo por atender a nichos de mercado. Alguns dos mais relevantes são $O$ Rei do cinema: a extraordinária bistória de Luiz Severiano Ribeiro, o homem que multiplicava e dividia, sobre o patriarca do Grupo Severiano Ribeiro, um empresário que foi dono da maior cadeia de salas de exibição do Brasil, uma trajetória que se confunde com a própria história do cinema brasileiro. Escrito pelo jornalista Toninho Vaz, foi editado pela carioca Record em 2008. Em 2011 temos Salas de cinema Art Déco no Rio de Janeiro, de Renato Gama e Rosa Costa, da Apicuri, também do Rio de Janeiro. Em 2012 aparece Cine Bijou, de Marcelo Coelho e Caco Galhardo, editado em São Paulo pelo SESC e Cosac Naify, um retrato revelador sobre a sala especializada em filmes de vanguarda na capital paulista.

De lá também vem o Cinema japonês na Liberdade, o bairro reduto de imigrantes japoneses e seus descendentes na cidade de São Paulo, responsável pela difusão do melhor do cinema nipônico no Brasil, escrito pelo antropólogo Alexandre Kishimoto e lançado em 2013 pela Estação Liberdade. Seguindo os estudos históricos sobre exibição no Brasil, também destacamos o livro Cinematographo em Nictheroy: história das salas de cinema de Niterói (Niterói, Niterói Livros/INEPAC, 2012), de Rafael de Luna Freire, fruto de uma pesquisa pioneira sobre a exibição cinematográfica na antiga capital do Estado do Rio de Janeiro. Na mesma seara, a obra A segunda Cinelândia carioca: cinemas, sociabilidade e memória na Tijuca, já publicada em duas edições (Rio de Janeiro, $1^{\text {a }}$ edição por Multifoco, 2010 e $2^{\mathrm{a}}$ edição por Mórula, 2012) de Talitha Ferraz.

\subsection{Cinema e Educação}


Telas que ensinam: midia e aprendizagem, do cinema às tecnologias digitais é um livro de Samuel Pfromm Netto lançado pela Alínea, em 2001, girando em torno das possibilidades de ensino à luz dos novos meios disponíveis. Quase a mesma estratégia utilizada por Marcos Napolitano em 2003, em obra da Contexto intitulada Como usar o cinema em sala de aula, onde o autor propõe a exibição de filmes como um recurso rico e lúdico de aprendizagem. Roseli Pereira Silva, psicopedagoga, centra seu livro Cinema e Educação, editado em São Paulo pela Cortez em 2007, em dois aspectos: o combate aos preconceitos e o uso do cinema de modo pró-ativo. Já Rosália Duarte, no livro homônimo Cinema e Educação, este editado pela Autêntica de Belo Horizonte em 2009, aborda as duas práticas como formas de socialização dos indivíduos e instâncias que produzem visões de mundo, identidades e saberes. Avança na discussão sobre a "competência para ver", uma competência que se estende ao ensino de idiomas, como o prova o livro Movie Takes: a magia do cinema na sala de aula de Grace Cristiane Thiel e Janice Cristine Thiel, vindo de Salvador através da Aymara, em 2009.

Filmes para ver e aprender, organizado por Áurea Castilho e publicado pela Qualitymark em 2010 busca estudar percepções humanas em relação a situações mostradas pelo cinema. Outras terras à vista: cinema e educação do campo, organizado por Aracy Alves Martins e outros, da Autêntica em 2010, vai bem longe na revisão de alguns filmes brasileiros dos anos 1960/70, buscando neles as consequências de uma reforma agrária falida para desmanchar os estereótipos da população rural. Organizado por Edileusa Penha de Souza e editado pela Mazza de Belo Horizonte é Negritude, Cinema e Educação: caminhos para a implementação da Lei 10.639/2003, em dois volumes, foi lançado em 2011 e são como um roteiro de questões étnico-raciais capazes de extrair de alguns filmes debates sobre racismo, discriminação e diversidade. Mônica Fantin, pela Annablume, lança também em 2011, seu livro Crianças, cinema e educação: além do arco-íris, um trabalho sobre recepção e modos de apropriação das narrativas cinematográficas por crianças do Brasil e da Itália.

O ano 2011 viu aparecer ainda o livro Lanterna mágica: infância e cinema infantil, do jornalista e crítico João Batista Melo, pela carioca Civilização Brasileira. Um panorama amplo do cinema infantil, abordando influências e referências, a relação com o marketing travestido em algumas obras, entre outros temas. Educação e Cinema: dialogando para a formação de poetas, de Lucilla da Silveira Leite Pimentel, pela Cortez em 2013 invoca o papel de agente transformador do professor através da redescoberta e da experiência da humanização possíveis através da ficção poética das imagens.

Já Cinema e educação: reflexões e experiências com professores e estudantes de educação básica, dentro e "fora" da escola, do mesmo ano e lançada pela Autêntica de Belo 
Horizonte, é uma obra de Adriana Fresquet que pensa o cinema como instrumento de cognição dos universos sociais e privados, que ensinar a desaprender uma existência automatizada. Um modo de vida por descontinuidades, paradigma da contemporaneidade, é uma das lições que o cinema pode revelar, na supressão de imagens e no esvaziamento da narratividade, e é isto de que trata $A$ leitura pelo olhar do cinema, que Eliana Yunes lançou em 2013 pela Reflexão de São Paulo. Preocupação semelhante à de Deborah Rosária Barbosa e Tales Vilela Santeiro em $A$ vida não é filme?:reflexões sobre psicologia e cinema, editada pela EdUFU em 2013, onde se trata do cinema na formação profissional no campo psíquico.

A coleção Cinema, cultura e educação da Autêntica engloba livros que se dirigem a nichos sociais específicos, voltados a pensar identidades, diferenças e ética a partir das questões problematizadas em alguns filmes. Todos os livros da série foram organizados por Inês Assunção de Castro Teixeira e José de Sousa Miguel Lopes e são $A$ mulher vai ao cinema (2005), $A$ escola vai ao cinema (2007), A infância vai ao cinema (2007), A diversidade cultural vai ao cinema (2007), A juventude vai ao cinema (2009) e A família vai ao cinema (2012). Perspectiva pedagógica mais pragmática se encontra em Fažendo cinema na escola, de Alex Moletta lançado pela Summus em 2014, que busca o protagonismo do aluno, orientando-o (e ao leitor comum) a pensar e produzir obras audiovisuais.

Cinema e Filosofia: ensinar e aprender filosofia com os filmes discute a capacidade transgressora da narrativa fílmica para além de um instrumento de expressão ou ilustração do pensamento filosófico. Escrito por Alessandro Reina, foi lançado em 2015 pela Editora Juruá de Curitiba. Inevitavelmente cinema: educação, política e mafuá, de Cézar Migliorin, lançado pela carioca Azougue em 2015, apresenta o projeto "Inventar com a diferença", que de 2013 a 2015 atuou em 234 escolas em todos os estados do país, visando o trabalho com cinema e direitos humanos, atentando para os dispositivos de criação. Finalmente, Sérgio Augusto Leal de Medeiros, pela Appris de Curitiba, lançou em 2016 o livro Imagens educativas do cinema tendo como perspectiva o processo formativo dos alunos através da educabilidade das imagens.

\subsection{História do cinema brasileiro}

Uma das principais características nos estudos de cinema brasileiro ocorridos nos últimos anos é a chamada revisão historiográfica, i.e., novos vieses de pesquisa sobre temas consagrados na cinematografia brasileira, chamando a atenção sobre aspectos até então pouco estudados na área. Assim, referente ao cinema silencioso no Brasil destacamosViagem ao cinema silencioso do Brasil (Rio 
de Janeiro, Azougue, 2011), organizado por Samuel Paiva e Sheila Schvarzman, fruto de um grupo de estudos de pesquisadores de São Paulo, que assistiram e discutiram sistematicamente todo o acervo de filmes brasileiros silenciosos depositados na Cinemateca Brasileira. Também graças ao acesso ao acervo da instituição de guarda paulista, entre outros arquivos consultados, destacamos os livros do historiador José Inácio de Melo Souza, pesquisador da Cinemateca Brasileira, Imagens do passado: São Paulo e Rio de Janeiro nos primórdios do cinema (São Paulo, Senac, 2004) e Salas de cinema e história urbana de São Paulo (1894-1930) (São Paulo, Senac, 2016). Ainda em relação ao período silencioso, também destacamos o livro Entre lanternas mágicas $e$ cinematógrafos: as origens do espetáculo cinematográfico em Porto Alegre 1861-1908 (São Paulo, Ecofalante, 2010) de Alice Dubina'Trusz.

Referente ao tema da recepção também se encontram estudos sobre a crítica de cinema e o cineclubismo no Brasil. Destacamos, então, Quando éramos jovens: bistória do Clube de Cinema de Porto Alegre (Porto Alegre, EdUFRGS/SMC, 2000) e A crítica de cinema em Porto Alegre na década de 1960 (Porto Alegre, EdUFRGS/SMC, 2008), ambos de Fatimarlei Lunardelli, Uma geração cinematográfica: intelectuais mineiros da década de 50 (São Paulo, Annablume, 2003), de Elysabeth Senra de Oliveira, Alex Viany: crítico e historiador (São Paulo/Rio de Janeiro, Perspectiva/Petrobras, 2003) de Arthur Autran, Cineclubismo: memórias dos anos de chumbo (Rio de Janeiro, Iluminária Academia, 2008) de Rose Clair, O cerol fininho da Baixada: histórias do cineclube Mate com Angu (Rio de Janeiro, Aeroplano, 2013) de Heraldo HB e Memória cineclubista de Pernambuco (Recife, Nano Produções, 2012)organizado por Isabela Cribari.

Um dos campos teóricos que se consolidou nas universidades brasileiras nos últimos anos é o dos estudos de som no audiovisual. Em termos editoriais, uma obra pioneira é O som no cinema brasileiro (Rio de Janeiro, 7 Letras, 2008) de Fernando Morais da Costa. Originalmente uma pesquisa de doutorado realizada na UFF, trata-se de uma história do cinema brasileiro do ponto de vista da tecnologia do som. Nessa seara teórica também destacamos $O$ cinema: uma arte sonora (São Paulo, Annablume, 2013) de Virgínia Flores e Som + Imagem (Rio de Janeiro, 7 Letras, 2012) organizado por Fernando Morais da Costa e Simone Pereira de Sá. Há estudos de caso sobre cineastas ou filmes específicos, dos quais destacamos, por abordar um longa dirigido por um cineasta brasileiro,Introdução ao desenho do som: uma sistematização aplicada na análise do longa-metragem Ensaio sobre a cegueira (João Pessoa, EdUFPB, 2013) de Débora Opolski. Também mencionamos Som direto no cinema brasileiro: fragmentos de uma bistória (Rio de Janeiro, Euphemia, 2016) de Marcio Câmara, um dos mais importantes técnicos de som da atualidade. 
$\mathrm{Na}$ relação entre música e cinema destacamos a reedição de Música popular: teatro e cinema (Rio de Janeiro, 34, 2000) de José Ramos Tinhorão, A música no cinema: os 100 primeiros anos (Rio de Janeiro, Rocco, 2004), em dois volumes, de João Máximo, $A$ arte de compor música para o cinema (São Paulo, Senac, 2014) de Eugênio Mattos,Sygkhronos: a formação poética musicaldo cinema (São Paulo, Via Lettera, 2003) de Ney Carrasco e $A$ música no cinema silencioso no Brasil (Rio de Janeiro, MAM-RJ, 2014) de Carlos Eduardo Pereira.

Outro tema que cresce são as pesquisas sobre o audiovisual a partir das discussões sobre sexualidade e gênero. A expressa maioria dessas pesquisas ainda se encontra circunscrita ao meio acadêmico. No entanto, essas reflexões ultrapassam os muros da universidade, sobretudo, por meio de capítulos de livros e textos de catálogos para mostras. Podemos afirmar que a discussão sobre a sexualidade no cinema se encontra em parcos livros brasileiros até os anos 2000. Uma obra do começo do novo século considerada inaugural é $A$ personagem homossexual no cinema brasileiro (Niterói, EdUFF, 2001) de Antônio Moreno, um estudo panorâmico sobre a representação da homossexualidade no cinema nacional. Antenado com as recentes pesquisas acadêmicas é Mulheres, homens, olhares e cenas (Curitiba, EdUFPR, 2011), organizado por Miriam Adelman e outros, com estudos sobre filmes brasileiros e estrangeiros a partir de vertentes teóricas contemporâneas. Também é o caso de Mulheres em foco: construções cinematográficas brasileiras da participação política feminina (São Paulo, Cultura Acadêmica, 2010) de Danielle Tega.

Outro viés que cresce na academia são os estudos sobre cinema e as relações étnico-raciais. Uma obra inaugural é $O$ negro brasileiro e o cinema de João Carlos Rodrigues, cuja $1^{a}$ edição é do final dos anos 1970, mas ganha duas novas publicações no século XXI (Rio de Janeiro, Pallas, 2001 e 2011). Outra obrachave é A negação do Brasil: o negro na telenovela brasileira (São Paulo, Senac, 2001) do pesquisador e cineasta Joel Zito Araújo, lançado em conjunto com o seu longa documental homônimo. Salta aos olhos a escassez de livros que abordam a relação entre os povos indígenas brasileiros e o audiovisual. No entanto, o que mais espanta é que existe uma sistemática produção teórica sobre o assunto no meio acadêmico, seja sobre a representação do índio no cinema, seja sobre a produção audiovisual realizada pelos próprios povos indígenas. Quase como uma exceção a parte sobre esse tema, podemos citar Serras da desordem (Rio de Janeiro, Azougue, 2008), organizado por Daniel Caetano, com artigos sobre o longa documental de Andrea Tonacci, e a

${ }^{9}$ A editora Pallas, sediada na cidade do Rio de Janeiro, possui um amplo catálogo voltado para a questão afro-brasileira. 
tradução do livro do brasilianista Robert Stam, intitulado Multiculturalismo tropical: uma história comparativa da raça na cultura e no cinema brasileiros (São Paulo, EdUSP, 2008).

Em relação aos estudos sobre o Cinema Novo, frisamos o original Gênese de Deus e o diabo na terra do sol (São Paulo/Salvador, Annablume/FGM/UFBA, 2005), de Josette Monzani, que estuda as várias versões do roteiro da obra de Glauber Rocha, aplicando a metodologia genética. Também sob essa relação interdisciplinar entre cinema e literatura, citamos Glauber Rocha e a literatura de cordel: uma relação intertextual (Rio de Janeiro, Casa de Rui Barbosa, 2007) de Silvia Nemer. Glauber Rocha: um olhar europeu (São Paulo, Instituto Lina Bo e P. M. Bardi, 2002) de Claudio Valentinetti, que apesar do título não é uma compilação do que os europeus refletiram sobre o cineasta baiano, mas uma reflexão sobre Glauber do autor italiano do livro, crítico de cinema. Também destacamos Cinema Novo: a onda do jovem cinema e a sua recepção na França (Campinas, Papirus, 2004) de Alexandre Figueirôa e A geração do Cinema Novo: para uma abordagem antropológica do cinema (Rio de Janeiro, Mauad, 2006) de Pedro Simonard. Podemos acrescentar a nova edição de Riverão Sussuarana (Florianópolis, EdUFSC, 2012), o único romance escrito e publicado por Glauber Rocha. Tampouco podemos deixar de citar a publicação na íntegra das duas entrevistas dadas por Glauber durante a sua estadia em Cuba no começo dos anos 1970 que foram a base para o longa documental de estreia de seu filho Eryk Rocha, não por acaso o organizador da publicação, Rocha que voa (Rio de Janeiro, Aeroplano, 2002). Também são reeditadas as obras referenciais sobre cinema brasileiro moderno do pesquisador Ismail Xavier, Sertão mar: Glauber Rocha e a estética da fome (São Paulo, Cosac Naify, 2007) e Alegorias do subdesenvolvimento: Cinema Novo, Tropicalismo, Cinema Marginal (São Paulo, Cosac Naify, 2012).

Aliás, logo no começo do novo século, Ismail lança um pequeno e importante livro, composto por três capítulos ensaísticos sobre o cinema brasileiro dos anos 1960 a meados dos 1980, intitulado O cinema brasileiro moderno (São Paulo, Paz e Terra, 2001). Soma-se ao esforço editorial de relançamentos a série de livros de Paulo Emílio Salles Gomes, inicialmente publicada pela editora paulistana Cosac Naify. A proposta original era publicar a obra completa de Paulo Emílio, o que infelizmente não se cumpriu devido à crise da editora, que culminou em seu fechamento em dezembro de 2015. Assim, chegaram a ser editados por esse projeto os livros Cemitério (São Paulo, Cosac Naify, 2007), obra inédita e inacabada que une ficção e memória política, o romance Três mulheres de três PPPês (São Paulo, Cosac Naify, 2007), Capitu (São Paulo,Cosac Naify, 2008), roteiro do filme de Paulo César Saraceni, escrito por Paulo Emílio e Lygia Fagundes Telles, e a caixa composta pelos livros Jean Vigo e Vigo, vulgo Almereyda (São Paulo, Cosac Naify, 2009). Recentemente algumas 
obras de Paulo Emílio passaram a ser editadas pela Companhia das Letras: $O$ cinema no século (São Paulo, Companhia das Letras, 2015), coletânea de críticas de filmes estrangeiros, e a republicação de seu romance Três mulberes de três PPPếs (São Paulo, Companhia das Letras, 2015). Por sua vez, uma coletânea de seus textos também é lançado pela importante coleção Encontros da editora Azougue, dedicada a pensadores e artistas brasileiros: Paulo Emílio Salles Gomes (Rio de Janeiro, Azougue, 2014), organizado por Adilson Mendes.

Sobre produções regionais ou períodos no cinema brasileiro tradicionalmente pouco estudados, como os anos 1980, destacamos Cinema brasileiro pós-moderno: o neon-realismo (Porto Alegre, Sulina, 2008) de Renato Luiz Pucci Júnior; A aventura do cinema gaúcho (São Leopoldo, EdUnisinos, 2002) de Luiz Carlos Merten,Pioneiros do cinema em Minas Gerais (Belo Horizonte, Crisálida, 2008) de Paulo Augusto Gomes e Cinema pernambucano: uma história em ciclos (Recife, SMC/FCC, 2000) de Alexandre Figueirôa.

É possível afirmar que uma das características do novo século é a redescoberta do Cinema Marginal. No começo dos anos 2000, a Mostra Cinema Marginal e suas fronteiras, realizada em São Paulo, Rio de Janeiro e Brasília, fremiu a cinefilia nacional, ao levar para as telas filmes considerados importantes na história do cinema brasileiro, até então praticamente invisíveis. A Mostra editou um cobiçado catálogo, formado por ensaios, depoimentos e uma filmografia comentada. Seu sucesso foi tanto que a produtora responsável por sua organização criou um portal na Internet sobre o tema, onde tais textos se encontram acessíveis, além de conseguir lançar uma coleção de DVDs. Em suma, na primeira década do século XXI, o Cinema Marginal é literalmente redescoberto por uma nova geração de espectadores e pesquisadores, e não por acaso tais filmes se tornaram referência estética para muitos realizadores do novíssimo cinema brasileiro. No meio acadêmico não é exceção, pois vemos um aumento no interesse por essa filmografia em muitas pesquisas.

Assim, podemos afirmar que um dos primeiros livros que flerta com o tema no século XXI, mas cuja pesquisa precede essa atual redescoberta, é Boca do lixo: cinema e classes populares (Campinas. EdUnicamp, 2006) de Nuno César Abreu, que ganha uma $2^{a}$ edição em 2016 acrescido de um DVD com entrevistas e filmografia da Boca. Outro sinal desse interesse pelo tema em âmbito editorial é a publicação em livros de textos, ensaios e entrevistas do cineasta Rogério Sganzerla em Por um cinema sem limites (Rio de Janeiro, Azougue, 2001),Rogério Sganzerla (Rio de Janeiro, Azougue, 2007), organizado por Roberta Canuto, e Edificicio Rogério: textos críticos 1e 2 (Florianópolis, EdUFSC, 2010), uma caixa com dois volumes de artigos de Sganzerla 
originalmente publicados em jornais brasileiros de grande circulação entre 1964 a 1967 e entre 1980 a 1990.

Essa redescoberta do Cinema Marginal abre debates historiográficos, ao pôr em discussão os experimentalismos estéticos do cinema brasileiro moderno, para além de rígidas categorizações em movimentos e escolas artísticas, como a velha dicotomia Cinema Novo versus Cinema Marginal. Podemos colocar nesse rol reflexões Poeta, herói, idiota: o pensamento de cinema no Brasil (Rio de Janeiro, Rios Ambiciosos, 2000) de Kátia Maciel, A utopia no cinema brasileiro: matrižes, nostalgia, distopias (São Paulo, Cosac Naify, 2006) de Lúcia Nagib, Um cinema brasileiro antropofágico? (1970-1974) (São Paulo, Annablume, 2008) de Guiomar Pessoa e $A$ invenção do cinema brasileiro: modernismo em três tempos (Rio de Janeiro, Casa da Palavra, 2014) de Paulo Antônio Paranaguá. Ressaltamos novamente que o debate historiográfico é o viés que articula boa parte dos recentes estudos sobre cinema nas universidades brasileiras. Nesse sentido, é sintomática a publicação de um livro-farol de Jean-Claude Bernardet sobre o tema, intitulado Historiografia clássica do cinema brasileiro: metodologia e pedagogia (São Paulo, Annablume, 1995), que recebeu uma 2a edição em 2008, pela mesma editora. Assim como a reedição de seu seminalCinema brasileiro: propostas para uma história (São Paulo, Companhia das Letras, 2009), originalmente publicado nos anos 1970.

\subsection{Cinema brasileiro contemporâneo}

A Retomada do cinema brasileiro propiciou uma busca de novas definições e, como todo recorte histórico, outras delimitações temporais. É um relativo consenso nos referirmos à produção cinematográfica brasileira desde o começo dos anos 2000 de Pós-Retomada. Assim, desde então, podemos assistir a uma recente produção de jovens realizadores, que possuem como espaço de visibilidade, a Mostra de Tiradentes e a Semana de Realizadores no Rio de Janeiro. Alguns críticos se referem a esses realizadores de "novíssimo cinema brasileiro", termo não consensual e bastante complexo.

Destaca-se uma das primeiras obras a buscar uma reflexão sistemática sobre a Retomada: Cinema Brasileiro 1995-2005, ensaios sobre uma década (Rio de Janeiro, Azougue, 2005), organizado por Daniel Caetano, com ensaios dos então redatores da revista eletrônica de cinema Contracampo, um dos periódicos virtuais brasileiros de cinema mais importantes da virada dos anos 1990/2000. Também mencionamos Cinema [de] novo: um balanço crítico da Retomada (São Paulo, Estação Liberdade, 2003) de Luiz Zanin Oricchio e O cinema da Retomada: depoimentos de 90 cineastas dos anos 90 (São Paulo, 34, 2002) de Lúcia 
Nagib. Por sua vez, Guido Bilharinho lançaO cinema brasileiro nos anos 90: novos filmes, pelo Instituto Triangulino de Cultura em 2000.

Em relação à Pós-Retomada se destacam Cinema brasileiro no século XXI: reflexões de cineastas, produtores, artistas, críticos e legisladores sobre os rumos da cinematografia nacional (São Paulo, Summus, 2012) de Francisco Ballerinie Cinema de garagem de Dellani Lima e Marcelo Ikeda (Rio de Janeiro, MFL, 2011), que se debruça sobre o cinema brasileiro independente realizado na primeira década do corrente século.É também Marcelo Ikeda o autor de Cinema brasileiro a partir da Retomada: aspectos econômicos e políticos (São Paulo, Summus, 2015).De caráter mais reflexivo, ao comparar o cinema brasileiro da década de $1960 \mathrm{com}$ o dos anos 2000 é Pai país, mãe pátria (Rio de Janeiro, IMS, 2016) de José Carlos Avellar. Referente a produções regionais, podemos citar Cinema gaúcho: diversidades e inovações (Porto Alegre, Sulina, 2009), organizado por Cristiane Freitas Gutfreind e Carlos Gerbase.

\subsection{Sobre autores e cineastas}

De caráter amplo se destaca $O$ cinema brasileiro no século XX: depoimentos (Rio de Janeiro, FBN, 2004), organizado por Isabella Souza Nicholas, que reúne depoimentos de realizadores, atores e atrizes do cinema brasileiro, do silencioso ao contemporâneo. Em relação aos diretores do Cinema Novo, podemos destacar Uma câmera na mão e uma ideia na cabeça: Glauber Rocha e a invenção do cinema brasileiro moderno (Curitiba, Prismas, 2015) de Frederico Osamam Amorim Lima, A primavera do dragão: a juventude de Glauber Rocha (Rio de Janeiro, Objetiva, 2011) do jornalista Nelson Motta, Glauber Rocha: cinema, estética e revolução (Jundiaí, Paco, 2016) de Humberto Pereira Rocha, Walter Lima Júnior (Rio de Janeiro, Casa da Palavra, 2002) de Carlos Alberto Mattos, Joaquim Pedro de Andrade, primeiros tempos (São Paulo, Alameda, 2013) de Luciana Corrêa de Araújo e $O$ cinema-poesia de Joaquim Pedro: passos da paixão mineira (Curitiba, Appris, 2016) de Meire Oliveira Silva. Também destacamos Helena Solberg: do Cinema Novo... ao contemporâneo (Belo Horizonte, Ed. da Autora, 2014) de Mariana Tavares. Também destacamos a tradução da obra da brasilianista Darlene J. Sadlier intitulada Nelson Pereira dos Santos (Campinas, Papirus, 2012).

Sobre o cineasta Humberto Mauro, consagrado pelo Cinema Novo, se destacam Humberto Mauro e as imagens do Brasil (São Paulo, Unesp, 2004) de Sheila Schvarzman e Humberto Mauro, cinema, história (São Paulo, Alameda, 2013) de Eduardo Morettin. Em relação a dois documentaristas pioneiros do cinema brasileiro, o major Luiz Thomaz Reis e Silvino Santos, são dedicados os livros A imagética da Comissão Rondon: etnografias fílmicas estratégicas (Campinas, 
Papirus, 2001) de Fernando de Tacca e Silvino Santos: o cineasta do ciclo da borracha (Rio de Janeiro, Funarte, $1^{\mathrm{a}}$ edição em 1999 e Manaus, EDUA, $2^{\mathrm{a}}$ edição em 2007) de Márcio Souza.

Ao cineasta, produtor e ator cômico AmácioMazzaropi são dedicados vários livros, alguns inclusive por ocasião de seu centenário de nascimento comemorado em 2012. Assim, citamos Mazzaropi: a imagem de um caipira (São Paulo, SESC, 1994), organizado por Andréa Cristina Bisatti, Mazzaropi: o jeca do Brasil (Campinas, Átomo, 2002) de Glauco Barsalini, Mažaropi: o caipira mais caipira do Brasil (São Paulo, Ilelis, 2009), do cineasta Galileu Garcia, que colaborou em alguns filmes do cineasta e cômico paulista, 100 anos depois: a história de Mažaropi (São Paulo, Nelpa, 2013) de José Daher, vulgo Zé Paraibuna, e $O$ jeca coronele a invenção do caipira paulista nas telas de cinema (Rio de Janeiro, Multifoco, 2015) de Thaís Valvano. Ainda no âmbito do cinema popular destacamos Maldito: a vida e o cinema de José Mojica Marins, o Zé do Caixão (Rio de Janeiro, 34, 1998) de André Barcinski e Ivan Finotti, a biografia do "pai do filme de terror brasileiro". Também no âmbito da Boca do Lixo é dedicado o livro O cinema e a crítica de Jairo Ferreira (São Paulo, Alameda, 2012) de Renato Coelho.

Sobre o singular cineasta Mário Peixoto se destacam os livros Jogos de armar: a vida do solitário Mário Peixoto - o cineasta de Limite (Rio de Janeiro, Lacerda, 2000), de Emil Castro, e Escritos sobre cinema (Rio de Janeiro, Aeroplano, 2000), organizado e comentado por Saulo Pereira de Mello, que reúne textos do próprio Mário Peixoto, incluindo a famosa crítica sobre Limite falsamente assinada por Eisenstein, que supostamente teria assistido o filme na Europa. Pela primeira vez, o texto é publicado sob o nome de seu verdadeiro autor, ou seja, o próprio cineasta Mário Peixoto. Também citamos Walter Salles: uma entrevista (Santa Maria da Feira, Cineclube da Feira, 2002) de Carlos Helí de Almeida e Câmera-faca: o cinema de Sergio Bianchi (Santa Maria da Feira, Cineclube da Feira, 2004) de João Luiz Vieira.

Em relação a textos de autoria de cineastas brasileiros, destacamos os ensaios Cinemancia (Rio de Janeiro, Imago, 2000) e Deslimite (Rio de Janeiro, Imago, 2011), ambos de Julio Bressane, assim como Adivinhadores de água: pensando no cinema brasileiro (São Paulo, Cosac Naify, 2005) de Eduardo Escorel. De caráter mais testemunhal citamos $O$ povo fala: um cineasta na área de jornalismo da TV brasileira (São Paulo, Senac, 2002) de João Batista de Andrade e Vida de cinema: antes, durante e depois do Cinema Novo (Rio de Janeiro, Objetiva, 2014) de Cacá Diegues. 


\subsection{Coletânea de críticas}

Destacamos as coletâneas de artigos feitos por críticos de cinema brasileiros. Dentro desse tópico frisamos o trabalho primoroso que é a edição da Revista de cinema: antologia (1954-1957/1961-1964) (Rio de Janeiro, Azougue, 2014), em dois volumes, organizado por Marcelo Miranda e Rafael Ciccarini, que reúne textos dessa importantíssima revista de cinema editada em Belo Horizonte nos anos 1950 e começo dos 1960. Sobre críticos em particular citamos Olhar crítico: 50 anos de cinema brasileiro (Rio de Janeiro, IMS, 2010) de Ely Azeredo, Um filme por dia: crítica de choque (1946-73), organizado pelo jornalista Ruy Castro, que reúne críticas de Antônio Moniz Vianna,Telégrafo visual: crítica amável de cinema (Rio de Janeiro, 34, 2004) de David E. Neves, organizado por Carlos Augusto Calil, e Relembrando o cinema pernambucano: dos arquivos de Jota Soares (Recife, FJN, 2006), organizado por Paulo C. Cunha Filho, que reúne as críticas de Jota Soares, pioneiro do cinema em Pernambuco. Destacamos a reedição de Trajetória crítica (São Paulo, Martins Fontes, 2011) de Jean-Claude Bernardet, livro originalmente lançado nos anos 1970.

\subsection{Prospecções abertas}

Definitivamente são muitos os domínios para os quais o cinema e os filmes se espraiaram e ganharam legitimidade intelectual e acadêmica. Sua extensão é incomensurável, por isto apresentamos aqui apenas uma mostra.

Sobre atuação, O vôo cego do ator no cinema brasileiro, de Nikita Paula, da Annablume, em 2001. A célebre preparadora de elenco Fátima Toledo é o objeto do livro Interpretar a vida, viver o cinema, escrito para a LiberArs de São Paulo por Mauricio Cardoso em 2014. Um dos grandes fotógrafos brasileiros, Walter Carvalho, assina o livro Fotografias de um filme, da Cosac Naify em 2003, concebido durante as locações do longa Lavoura Arcaica (2001), dirigido por Luiz Fernando Carvalho. Já Expor uma história: a fotografia do cinema, também escrito por um experiente fotógrafo, Ricardo Aronovich, foi editado pela Gryphus do Rio de Janeiro em 2004. Sobre um campo técnico em geral pouco estudado é $A$ arte em cena: a direção de arte no cinema brasileiro (São Paulo, Senac, 2014) de Vera Hamburguer. Já Paulo B. C.Schettino trouxe à baila uma série de depoimentos de profissionais da indústria com Diálogos sobre a tecnologia do cinema brasileiro, ainda em 2007 pela Ateliê.

Por sua vez, os trailers foram estudados por Claudia Melissa em Trailer: cinema e publicidade no mesmo rolo, numa edição da Goânia, em 2007. Máximo Barro apresenta uma bela coleção de peças em O Cinema em cartaz, edição da FAAP 
em 2008 e no ano seguinte os geógrafos Roberto Lobato Correa e Zeny Rosendahl organizam pela EdUERJ a obra Cinema, música e espaço. A terra, dentro da representação de seus usos no cinema e a partir de seus pertencimentos na formação social brasileira, é o tema de Imaginação da terra: memória e utopia no cinema brasileiro, de Heloisa Maria Murgel Starling, pela EdUFMG, em 2012.

De caráter mais interdisciplinar é Cinema, velhice e cultura: cinedebate, organizado por Neusa Maria Mendes de Gusmão e lançado pela Alínea de Campinas em 2005. Mesmo a gastronomia marcou presença no livro O cinema vai à mesa: histórias e receitas, do popular crítico Rubens Edwald Filho que com Nilu Lebert lançou-o pela Melhoramentos em 2007. Cinema na Universidade, organizado por Noeli Gemelli Reali para a Argos de Chapecó, em 2007 trouxe os comentários colhidos entre os debatedores dos filmes selecionados, pautados por suas vivências de docentes, profissionais liberais, ativistas políticos, cineastas, roteiristas e acadêmicos, montando um painel bem expressivo dos modos de ler... e de se aproveitar o cinema.

Tratando da autorreflexividade Todo filme é sobre cinema, de Aldus Nei Duclós, editada pela gaúcha Unisinos em 2014, propõe que o cinema é uma arte voltada para si mesma e se basta. Por sua vez, Cristine Koehler Zanella e Edison José Neves Júnior organizam pela editora Fino Traço, de Belo Horizonte, os livros As relações internacionais e o cinema - volume 1: espaços e atores transnacionais, em 2015, e As relações internacionais e o cinema - volume 2: Estados e conflitos internacionais, em 2016.

\section{Discussão}

Diante dos dados coletados, podemos afirmar que ainda se publica pouco sobre cinema e, especialmente, sobre cinema nacional no Brasil. Por outro lado, é evidente que em comparação às décadas passadas, são publicados muito mais livros sobre cinema e audiovisual hoje em dia do que antes. No entanto, muitos aspectos da área ganharam relevância na pesquisa acadêmica, como os estudos de som, a preservação audiovisual e pesquisas sobre o Cinema Marginal, por exemplo, assim como os estudos de gênero e questões étnico-raciais. Trata-se de campos em plena expansão nas universidades brasileiras. Porém, podemos afirmar que o mercado editorial brasileiro ainda não absorveu a expressa maioria dessas pesquisas. Também é significativo notar que a maioria esmagadora dos livros sobre cinema e audiovisual no Brasil é publicada por editoras concentradas na Região Sudeste, especialmente, no eixo Rio de Janeiro-São Paulo. 


\section{Conclusões}

O começo do século XXI é marcado pela ampla expansão do ensino universitário no Brasil, conforme as políticas públicas implantadas durante os dois governos presidenciais de Lula. No entanto, podemos assistir essa expansão no campo do cinema e audiovisual já no final dos anos 1990, quando são criados vários cursos de Graduação na área, devido a um forte interesse pelo tema, vinculado ao reerguimento da produção audiovisual nacional, e pelo barateamento dos custos de produção por conta da tecnologia digital. Por sua vez, os Programas de Pós-Graduação sofrem, de fato, um boom no presente século, o que acarreta um crescimento exponencial no número de pesquisas voltadas ao cinema, à televisão e ao audiovisual, de modo em geral. Por conta desse cenário, testemunhamos um incremento no mercado editorial brasileiro em relação a títulos voltados aos estudos de cinema e audiovisual, inclusive para atender uma demanda crescente de estudantes e pesquisadores sobre o tema. Portanto, em comparação ao final do século passado, podemos afirmar que nunca se publicou tanto sobre cinema e audiovisual no Brasil como nos últimos quinze anos.

Frente ao atual tamanho dos estudos de cinema e audiovisual postulamos que ainda é muito pouco o volume das publicações. Porém, acreditamos que tal cenário não deverá sofrer grandes mudanças nos próximos anos devido às recentes dificuldades financeiras sofridas pelas editoras brasileiras, às quais se soma o presente contexto de cortes em editais públicos e auxílios a publicação, o que afeta profundamente as editoras universitárias e imprensas públicas. Não podemos deixar de citar que as agudas mudanças políticas sofridas pelo país em 2016 confirmam as nossas conclusões, ainda mais se levarmos em conta a inusitada e bizarra fusão do Ministério da Ciência, Tecnologia e Inovação (MCTI) com o Ministério das Comunicações (MC). Medida que desagradou a comunidade científica, uma vez que entidades de prestígio da área, algumas mais antigas do que o próprio MCTI, como o CNPq e a FINEP (Financiadora de Estudos e Projetos), foram rebaixadas ao status de quarto escalão na reestruturação do novo Ministério, o que significa uma perda considerável de autonomia administrativa e financeira. Em suma, diante do conturbado cenário que se apresenta a partir da derrubada do Governo Dilma, recursos para a educação e pesquisa serão mais escassos. No entanto, assim como o cinema é um feixe de luz que corta uma sala escura, almejamos que a consolidação do campo de reflexão sobre cinema e audiovisual continue, mesmo que seja em tempos turvos. 


\section{Referências}

Barone, J. G. (2011). Comunicação e indústria audiovisual: assimetrias, dilemas e axiomas do cinema brasileiro nos anos 2000. In. Famecos, Porto Alegre: v. 18, n. 3 .

Forcine (2015). Forcine (texto institucional). Online. Disponível em:

<http://forcine.org.br/site/quem-somos/>. Acesso em: 12/10/2016.

Souza, J. I. M. (Org.). (2002/2003). Um balanço do cinema brasileiro na universidade.In. Mnemocine (Online). Disponível em:

$<$ http://www.mnemocine.com.br/bancodeteses/cinebrasileironauniversidade htm.htm>. Acesso em: 09/02/2017. 


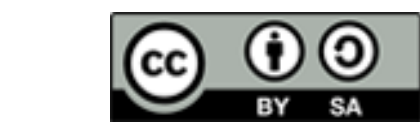

Licencia Creative Com0mons

Miguel Hernández Communication Journal

mhjournal.org

\section{Cómo citar este texto:}

Antônio Carlos Amancio y Fabián Núñez (2017): "Para além do ano 2000, pensar cinema no Brasil", en Miguel Hernández Communication Journal, nº, pp. 121 a 149. Universidad Miguel Hernández, UMH (Elche-Alicante). Recuperado el _ de de 20 de: [link del artículo en mhjournal.org] 
